\title{
CES
}

COOPERATIVISMO E ECONOMÍA SOCIAL

Núm. 43 (2020-2021), páxs. 257-263

ISSN: 2660-6348

\section{ANOTACIÓN A LA SENTENCIA 123/2020 DEL JUZGADO DE LO MERCANTIL DE GIJÓN DE 3 DE SEPTIEMBRE}

\author{
COMMENT TO THE JUDGEMENT 123/2020 OF THE \\ COMMERCIAL COURT OF GIJON FROM THE 3RD SEPTEMBER
}

\author{
Marta Cernadas Lázare*
}

Profa. Dra. del Área de Derecho Mercantil de la Facultad de Derecho de la Universidade da Coruña. Dirección de correo electrónico: marta.cernadas.lazare@udc.es 



\section{HECHOS DE LA SENTENCIA}

$\mathrm{L}$

a sentencia objeto de anotación trae causa en el desacuerdo entre un socio cooperativista y la Cooperativa Transportes Asturianos (TRANSASTUR) y el Fondo de Auxilio de Transastur. El objeto de dicha discrepancia proviene de la negativa de la Cooperativa de hacerse cargo de la reparación del vehículo de la actora por los daños sufridos en un siniestro.

Tal y como se relata en la sentencia, la demandante considera que los daños ocasionados en el vehículo deben ser cubierto por la Cooperativa a través del Fondo de Auxilio, dado que estos son consecuencia de una defectuosa carga y estiba de las mercancías que no le es imputable. Por su parte, la Cooperativa sostiene que el siniestro sí es imputable a la parte actora debido a que el mismo tiene causa en que la mercancía estaba mal amarrada o mal acondicionada.

La decisión de la Cooperativa de no hacerse cargo de la reparación del vehículo de la actora fue adoptada en su Asamblea General por veinte votos en contra, diecinueve votos a favor, tres votos en blanco y una abstención. Esta decisión fruto de tres acuerdos sociales son objeto de impugnación por parte de la demandante, quien solicita su nulidad. Asimismo, en este procedimiento se solicita subsidiariamente que se que se reconozca el carácter de cargador contractual de la Cooperativa.

\section{IMPUGNACIÓN DE ACUERDOS}

En este asunto, la actora solicita la declaración de nulidad de tres acuerdos sociales: el acuerdo de 5 de abril de 2019 del Consejo Rector de Transportes Asturianos; el acuerdo de 15 de junio de 2019 de la Asamblea General Extraordinaria de Transastur; y el acuerdo de 20 de junio de 2019 del Consejo de Gobierno del Fondo de Auxilio de Transastur. Justamente, es por medio de estos acuerdos por los que la Cooperativa adopta la decisión de no reparar los daños sufridos en el vehículo de la actora.

La demanda a través de la cual se solicita la impugnación de dichos acuerdos sociales se presentó el 26 de julio de 2019 a las 10:26. En contestación, la demandada alega que la acción de impugnación de la Asamblea General ha caducado, al celebrarse esta el 15 de junio de 2019, por lo que invoca la excepción de caducidad de la acción. La Cooperativa entiende que se han superado tanto el plazo de caducidad de treinta días que establecen los Estatutos sociales en su artículo 60, como el plazo de cuarenta días recogido en el artículo 58 de la Ley de Cooperativas del Principado de Asturias (Ley 4/2010, de 29 de junio, de Cooperativas del Principado de Asturias). Por su parte, la actora sostiene que dicha acción de 
impugnación no ha caducado dado que, en aplicación del artículo 185 de la Ley Orgánica del Poder Judicial (Ley Orgánica 6/1985, de 1 de julio, del Poder Judicial), deben excluirse del cómputo del plazo los días inhábiles.

Antes de proceder a valorar esta cuestión, la sentencia del Juzgado de lo Mercantil de Gijón realiza una breve exposición de la jurisprudencia del Tribunal Supremo sobre la excepción de caducidad (STS de 15 de marzo 2016, ECLI:ES:TS:2016:967 y STS de 19 de abril 2016, ECLI:ES:TS:2016:1780). En primer lugar, se refiere a la diferencia entre la impugnación de los acuerdos nulos y los anulables. En este sentido, recuerda «que la nulidad de pleno derecho ipso iure tiene lugar en los casos en que un acuerdo o actuación va contra una norma imperativa o prohibitiva». Por su parte, la anulabilidad se puede ejercitar cuando existe un vicio en el acuerdo o actuación que permiten invalidarlo o anularlo.

Respecto al caso concreto, la sentencia explica que la acción de nulidad está sometida al plazo de caducidad de cuarenta días fijado en el artículo 58 de la Ley de Cooperativas de Asturias. La importancia del plazo radica en que cuando este transcurre no puede ejercitarse la acción. Tal y como se declara, «la caducidad o decadencia del derecho surge cuando la ley o la voluntad de los particulares señalan un plazo fijo para la duración de un derecho, de tal modo que una vez transcurrido el mismo no puede ser ya ejercitado». La propia Ley de Cooperativas también establece, en el citado precepto, el dies a quo para el cómputo del plazo, que es desde la fecha de adopción del acuerdo.

La sentencia prosigue con la diferencia entre caducidad y prescripción, las cuales no cabe confundir porque, mientras la prescripción «tiene por finalidad la extinción de un derecho contra la razón objetiva de su ejercicio por el titular», la caducidad «solo atiende al hecho objetivo de la falta de ejercicio dentro del plazo prefijado de índole preclusiva». Consecuentemente, el plazo de caducidad establece el límite dentro del cual puede ejercitarse el derecho, por lo que la ausencia de su utilización en plazo implica la decadencia del derecho.

Tras este análisis, se examina si el plazo de caducidad se trata de un plazo procesal o de un plazo sustantivo. De ser un plazo procesal serían de aplicación el alegado artículo 182 de la LOPJ y el artículo 133 de la Ley de Enjuiciamiento Civil (Ley 1/2000, de 7 de enero, de Enjuiciamiento Civil). Por su parte, si se considera un plazo sustantivo la norma aplicable es el artículo 5 del Código Civil. Esta distinción no carece de importancia dado que su determinación implica el cómputo o no de los días inhábiles. Tal y como establece el artículo 5 del CC, «en el cómputo civil de los plazos no se excluyen los días inhábiles», mientras que si estamos ante un plazo procesal no se computan ni los días inhábiles, ni el mes de agosto (artículos 182 de la LOPJ y artículo 133 de la LEC). 
No obstante, no existe debate alguno sobre la naturaleza procesal o material del plazo de caducidad dado que el Tribunal Supremo ha señalado en numerosas ocasionases que se trata de un plazo de Derecho sustantivo o material (entre la jurisprudencia del TS, la sentencia anotada cita STS de 10 de noviembre de 1994 y STS de 9 de febrero de 2016, ECLI:ES:TS:2016:657). Por consiguiente, no cabe excluir de su cómputo los días inhábiles.

En el caso comentado, se pretende impugnar el acuerdo de la Asamblea General de 15 de junio de 2019, pero la demanda fue presentada el 26 de julio de 2019. Como se aprecia, la demanda está fuera del plazo de cuarenta días que establece el artículo 58 de la Ley de Cooperativas de Asturias porque el cómputo de este plazo se inicia, como bien indica el citado precepto, el día en que se tomó el acuerdo y no el día siguiente. Consecuentemente, la acción de nulidad del acuerdo de la Asamblea General ha caducado por no haberse presentado en plazo la demanda.

Por su parte, por lo que se refiere a la impugnación del acuerdo de 20 de junio de 2019 del Consejo de Gobierno del Fondo de Auxilio de Transastur es necesario precisar que este no es el órgano donde se deben dirimir las discrepancias entre los socios y el Fondo. El artículo 60 de los Estatutos del Fondo de Auxilio establece cuál es el procedimiento impugnatorio a seguir. Dicho precepto dispone que, «cualquier discrepancia que se suscite en la interpretación y aplicación del reglamento del Fondo, entre un socio y el mismo será tratada en la próxima Asamblea General a celebrar, y esta será informada, primero por la Junta Directiva del Fondo y en segundo lugar por la persona discrepante, y además con la audiencia de la Junta Directiva de Transastur, como órgano supremo al que pertenece este servicio. Si aún así no existe entendimiento entre las partes, estas con renuncia del propio fuero se someten a la jurisdicción de los Juzgados y tribunales de Gijón, en el plazo de 30 días siguientes a partir de la decisión final de la Asamblea General».

En vista de este procedimiento, es preciso conocer si existe algún acuerdo de la Asamblea General susceptible de ser impugnada. En el caso comentado, el único acuerdo de la Asamblea General es el de 15 de junio de 2019 y, como se ha relatado, el plazo de impugnación ha caducado por lo que los acuerdos sociales frente a los que se pretende la nulidad han devenido firmes. En consecuencia, se desestima la primera pretensión de la parte actora.

\section{CONTRATO DE TRANSPORTE}

La demanda presentada por la actora solicita subsidiariamente que se «declare el carácter de cargador contractual de la Cooperativa de Transportes Asturianos (Transastur) en el servicio de transporte terrestre de mercancías durante el cual tuvo lugar el siniestro y su responsabilidad íntegra en el mismo» como cargador responsable contractualmente de la estiba de la mercancía que produjo los daños en el vehículo de la demandante. 
En el caso anotado, se considera probado que el siniestro acaecido trae causa en la mala estiba de las mercancías. De acuerdo con la prueba documental, los daños sufridos por el vehículo de la actora se deben al corrimiento o desplazamiento interno de la mercancía mal trincada o amarrada. Si bien la causa del siniestro no se discute, demandada y demandante discrepan sobre quién es responsable de los daños derivados. Mientras que la parte actora considera que la responsabilidad recae sobre la Cooperativa, esta sostiene que el socio cooperativista es el culpable de la defectuosa estiba.

En este asunto, según se desprende del relato de hechos, existen tres sujetos implicados: la empresa cargadora, la Cooperativa porteadora y el socio cooperativo como porteador efectivo. $\mathrm{Si}$ atendemos a la responsabilidad de los porteadores efectivos regulada en el artículo 6 de la Ley del contrato de transporte terrestre de mercancías (Ley 15/2009, de 11 de noviembre, del contrato de transporte terrestre de mercancías), se aprecia que «cuando el porteador que haya contratado directamente con el cargador contrate, a su vez, la realización efectiva de la totalidad o una parte del transporte con otro porteador, quedará obligado frente a este como cargador». En virtud de este precepto, la Cooperativa está obligada frente al socio como cargadora contractual. No obstante, esta respuesta no determina que la Cooperativa deba hacerse cargo por los daños derivados del siniestro. Y, de hecho, esta escusa su responsabilidad en el artículo 8 de sus Estatutos Sociales, dado que entiende que el siniestro se ha producido por una defectuosa estiba imputable al socio.

En este contexto, la sentencia del Juzgado de lo Mercantil de Gijón recuerda que, según el artículo 20 de la Ley del contrato de transporte terrestre de mercancías, las operaciones de carga y estiba de las mercancías serán realizadas por el cargador, salvo que el porteador haya asumido expresamente estas operaciones. Asimismo, declara que, tal y como disponen el régimen de exoneración de la responsabilidad del porteador recogido en los artículos 48 y 49 de la ley, el porteador no es responsable de los hechos ocasionados por culpa del cargador, así como los derivados de la carga y estiba efectuada por este.

En este caso, la carta de porte presentada como prueba no contiene ninguna reserva en virtud de la cual el porteador asuma las funciones de carga y/o descarga de la mercancía. De igual modo, el protocolo de la empresa cargadora sugiere que la carga y estiba de las mercancías fue realizada, tal y como este dispone, por los operarios de la dicha empresa mientras el conductor permanece a tres metros de distancia. Por consiguiente, al no ser realizada por el porteador la carga y estiba, este queda exonerado de responsabilidad. Según la sentencia, la Ley del contrato de transporte terrestre de mercancías establece las responsabilidades de los intervinientes en el contrato tanto «para los daños causados a las mercancías como, por extensión, por los originados por las mercancías», dado que lo «determinante es la 
delimitación de las funciones y responsabilidades de los diferentes intervinientes en las operaciones».

Finalmente, sobre la base del artículo 5 de la Ley del contrato de transporte terrestre de mercancías, la sentencia afirma el carácter de cargadora de la Cooperativa ante el socio transportista. Consecuentemente, Transastur debe hacerse cargo de los daños ocasionados en el vehículo de la actora por causa del siniestro, «sin perjuicio del derecho de repetición que pudiera asistirle frente al expedidor», como efectivo causante del daño. 